\title{
A Framework of an Improved Model for Evaluation of Instructors' Performance in Higher Institutions of Learning
}

\author{
Aranuwa Felix Ola ${ }^{1}$ and Prof (Dr). Sellapan Palaniappan ${ }^{2}$ \\ ${ }^{I}$ School of Science and Engineering, Malaysia University of Science and Technology, Selangor, Malaysia \\ ${ }^{2}$ School of Science and Engineering, Malaysia University of Science and Technology, Selangor, Malaysia
}

\begin{abstract}
The development of an improved and intelligent model for evaluation of instructors' performance in higher institutions of learning especially in the developing countries can be well motivated from three points of view: the recent policies mandating high stakes evaluation of instructors and learning system which are at the forefront of the education reforms agenda, the reasoning behind the degree of difference in the students' academic performance and outcomes, and the quest for an optimal algorithm suitable for predicting instructors' performance. Worldwide national policies on higher education are giving increasing importance to improve the quality of education offered. Consequently, the evaluation of instructors' performance is especially relevant for the academic institutions as it helps to formulate efficient plans to guarantee quality of instructors and teaching learning process. This work is directed at designing a framework of an improved and intelligent instructors' performance evaluation that can evaluate, predict instructors' performance as well as recommend necessary actions to be taken.
\end{abstract}

Keywords: Conceptual framework, Improved model, National policy, Optimal algorithm, Performance evaluation

\section{Introduction:}

The declining standard and the degree of difference in the academic performance of students in tertiary institutions in recent times has been and is still a source of great concern and of research interest to higher education managers, researchers, parents and governments because of the importance that education has on the national development [1], [2], [3]. The ever-increasing analysis on the outcome being produced by colleges and universities has not only been generating questions about the quality and efficiency of their teaching workforce and learning systems, but has continued to occupy a major place on the agenda of higher education leaders and teachers' performance evaluation is becoming a dominant theme in the school reform efforts [4], [5], [6], [7]. According to Andrew, Bankole, and Olatunde (2010)[8], a large mismatch appears to exist between university output and labour market demand in recent times. Their findings show that the performances of recent graduates have clearly deteriorated, primarily because of the operational policies and inadequate level of skilled human resources, especially the quality of university-trained portion of the work force. Deteriorating quality perception is also supported by the results from empirical research of Chiemeke, Longe, and Shaib (2009) [9].

The Obama led administration made state support of rigorous teachers' evaluation systems a precondition for competition in "Race to the Top", and has laid out a blueprint for the reauthorization act in which teacher effectiveness defined by evaluation of on-the-job performance is an important facet [10]. Selfproclaimed education reformers such as Bill Gates, Davis Guggenheim and Michelle Rhee in their submission posited that teachers' evaluation should be at the forefront of the education reform agenda and that evaluation results be used as the basis for making decisions about hiring, disciplining, compensating, awarding tenure to and sanctioning ineffective teachers [11]. One of the reasons for this may not be farfetched from the fact that the strength of good education in any educational institution depends on the quality of the academic staff in that institution; and there is no satisfactory substitute for competent staff that possesses sound educational philosophy and dynamic leadership [12]. As the most significant resource in schools, teachers are vital to improve student outcomes and raise education standards. Hence, improving the efficiency and equity of schooling depends, in large measure, on ensuring that teachers are highly skilled, well resourced, and motivated to perform at their best. From this perspective, teachers' performance evaluation is a vital step in the drive to improve the effectiveness of learning system and raise educational standards. According to Denisi and Pritchard (2006)[13], a central reason for the employment of performance evaluation is performance improvement (initially at the level of the individual workforce, and ultimately at the level of the institution). Other fundamental reasons include basis for employment decisions (e.g. promotions, career advancement, performance reward, sanctions, etc). Additionally, performance evaluation can aid in the formulation of criteria and selection of individuals who are best suited to perform required organizational tasks [14]. It can be part of guiding and monitoring employee career development and improvement. 
With the above facts and the national policies mandating high stakes evaluation of teachers and the learning system at the forefront of popular school reforms agenda, in which all academic institutions are increasingly required to monitor the performance of their learning and teaching systems [7], [15],. There is no doubt educational institutions both in developing and developed countries have an obligation to deliver value for investment to the bodies that fund them. Moreso that university performance are often judged by the quality and reputation of the awards they provide and the product they produce [16]. Evaluation of teachers' practice and performance evaluation in higher institutions is definitely not a new trend, but what is new is deep interest to enhance ways of evaluating teachers' performance considering the weakness of the classical methodologies and contentious issues on accuracy and dependability [17],[18]. Hence, the need to design an intelligent evaluation system for apt evaluation of teachers performance in higher institutions in order to have evidence to inform academic policies that are aimed at overcoming the limitations of the classical methodologies.

\section{Literature Review}

According to Manasa and Reddy, (2009) [14]; Abu-Doleh and Weir, (2007) [19], performance evaluation is defined as a systematic process of evaluating an individual worker's job performance and effectiveness in relation to certain pre-established criteria and organizational objectives. Following this definition, teachers' performance evaluation can be defined as a systematic process of evaluating instructors performance and competence in relation to certain pre-established criteria, standards and school objectives. As mentioned earlier, evaluation of teachers' practice and performance evaluation in higher institutions is definitely not a new trend, but what is new is deep interest to enhance ways of evaluating teachers' performance. Researchers at different levels have proposed and used wide-ranging approaches to evaluating teachers' performance. However, the efficiency and dependability of the classical methods has been controversial [10], [20], [21], [22]. As a result there was no standard method or computerized solution for evaluating teachers' performance that capture the complex nature of the art and science of teaching and learning system in the tertiary institutions [23].

\subsection{Performance Evaluation Methods}

Two types of performance evaluation methods identified and widely used in the literature are: formative and summative evaluations [7], [24], [25], [26], [27], [28], [29]. Meanwhile, early in the history of teachers' performance evaluation, educators were evaluated based on traits or characteristics which may or may not have been related to performance, and yet no significant body of knowledge confirms to the fact that effective teaching performance is dependent on specific traits. As a result, this form of evaluation was discarded [17], [30]. Formative evaluation refers to a qualitative evaluation on the teacher current practice (teaching assessment), aimed at identifying strengths and weaknesses and providing adequate professional development opportunities for the areas in need of improvement. Formative evaluation involves the use of classroom observations, student evaluation report etc., as tools to measure the performance and effectiveness of a teacher. The overall intention is to provide informative feedback to assist faculty in improving the effectiveness of their teaching performance [31]. While summative evaluation is described as an indispensable source of documentation and recognizable way to evaluate teachers, providing summary statements of a teacher's capabilities through inspection, examination or interviews, in order to measure aptitude and knowledge, to ensure that required standards are met, or to promote level of performance for immediate recognition [25]. It is used to determine the worth and career advancement of a teacher, assess that teachers are adopting the actions and best practices which improve student outcomes. Summative evaluation gives crucial information about the teacher being evaluated relatively to what is considered as standards. Hence, summative evaluation is an indispensable source of documentation to hold teachers accountable for their professionalism. In many institutions, it involves the use of annual performance evaluation report (APER) and interview as instruments to measure teachers' performance and effectiveness [21]. Although, various research studies have been conducted to support the validity, reliability and usefulness of these tools at different levels; however, there are considerable debates about their dependability and how teacher evaluation should be used to improve schools standard and academic performance [10], [18], [21]. Critics have claimed that formative method (e.g student rating system) is too subjective (i.e biased and one-sided) [24], [32].

Traditionally faculties have been skeptical about this, the negative feelings often spring from the fear that student ratings may not be reliable and may be used or misused for summative decision making purposes and such misuse can breed distrust and resentment between faculty and administrators on the part of instructors. Additionally, they often believe that students do not take evaluations seriously and ratings may encourage grade leniency [24], [33]. Okoro (1991) [34] observes that students sometimes fill in what they think the teacher would like rather than how they feel about him or what they are assessed. He also reasons that some teachers may treat students very leniently and may spend a lot of time joking with them in order to obtain favourable ratings. However, researchers recommended that when such data are going to be used, the instrument must be 
subjected to rigorous validity tests and analysis. Further, student rating data should be used in combination with other criteria in order to provide a better assessment, since any single measure of the evaluation will only emphasize one important element at the expense of others [35]. In the work of Nakpodia (2011) [21], he reported methodological weakness in the current ways of evaluating the performance and progress of teachers with respect to the Annual Performance Evaluation Report (APER). He claimed that this form of evaluation does not actually take consideration of all substantial evaluation components of academic staff progress performances, but the items of information on the report are used to determine whether the staff satisfies two out of the four conditions on which the promotion of academic staff is said to be normally based. The two conditions are: evidence of scholarly research publications; and evidence of effective service to the institution. He added some of the items in the rating scale are ambiguous and cannot be easily evaluated while; others are extraneous and irrelevant. However, he concluded that students' rating alone cannot provide all the relevant information required to evaluate the lecturers. Hence, a supplementary instrument should be used to obtain information dealing with such aspects of professional development e.g academic advancement, research publications and participation in academic conferences, workshops and seminars. He suggests, that if APER is going to be used, ambiguous sections should be eliminated from the instruments.

Based on the above facts and according to Steele et al., (2010) [36], teacher evaluation systems should employ a diverse set of measures to capture the complex nature of the art and science of teaching and learning system, which is inherently a multidimensional construct. Hence, the obvious need for improved teachers' evaluation system that includes a spread of verifiable and comparable teachers' performance that distinguish teachers' quality and effectiveness, which this research work is set to achieve. In this work, machine learning algorithms that are guided by teacher evaluation principles is proposed, focuses at addressing the following: modeling an improved teachers' performance evaluation technique based on data mining model integrating both formative and summative methods of teacher evaluation, proposing an optimal algorithm suitable for predicting teachers' performance, and presenting an intelligent teachers' performance evaluation system that can predict teacher's performance as well as recommend necessary action to be taken to aid school administrators in decision making and identifying background factors that affect faculty performance.

\subsection{Conceptual Framework to Analyze Teachers Evaluation}

According to OECD (2009) [37], designing a framework for teachers' evaluation involves a range of features. Firstly, it needs to be framed in the context of the overall objectives which is to improve student academic performance, outcomes and standards of education. Secondly, the purposes of the teachers' evaluation need to be clearly defined. In particular, it needs to be clear what aspects teacher evaluation seeks to monitor and measure. The framework also needs to establish strategies to address the tension between the typical purposes of improvement and the accountability in teachers' performance evaluation. Teachers' performance evaluation for improvement focuses on the provision of feedback useful for the improvement of teaching practices. It involves helping teachers to learn about, reflect on, and improve their practice [7]. This is formative in nature and it typically occurs within the account of the school context. The accountability function of teacher evaluation focuses on holding teachers accountable for their performance associating it to a range of consequences for their career. It seeks to set incentives for teachers to perform at their best. It typically entails performance-based career advancement and/or salaries, bonus pay, or the possibility of sanctions for underperformed teachers [38]. Teacher evaluation for accountability is summative in nature and usually involves evaluating performance at nodal points in a teacher's career. It also works as a means to provide recognition to teachers. Largely, teachers' performance evaluation contributes to creating a knowledge-rich teaching profession in which teachers develop a research role alongside their teaching responsibility, with teachers engaging more actively with new knowledge, and benefiting from support structures to generate improvement.

Thirdly, there needs to be a clear understanding of the responsibilities of the different educational actors within the teacher evaluation framework. Educational authorities at several levels, agencies in charge of quality assurance such as Ministry of Education (MoE), National Universities Commission (NUC), schools, teachers and students play different roles in ensuring improvement and accountability in the teaching profession. Government/Educational authorities play a major role in the conception and application of teachers' evaluation, since they set the national learning outcome objectives, agree standards for the teaching profession and establish the norms that regulate teachers' evaluation. In some countries, they play a direct role in the implementation and monitoring of teachers' evaluation procedures. This might include the design of specific evaluation tools and instruments, the determination of evaluation criteria, the distribution of evaluation duties, and the follow-up on evaluation results. In other countries, educational authorities establish general principles and guidelines only and give institutions considerable leeway to adapt the teachers' evaluation model to their particular circumstances [25]. 
Fourthly, there needs to be a reflection on the way teachers' evaluation articulates with the remaining components of the evaluation and assessment framework such as school evaluation, student assessment and system level evaluation. Since systems of school evaluation and teacher evaluation and feedback have both the objective of maintaining standards and improve student performance, there are great benefits from the synergies between school evaluation and teacher evaluation. To achieve the greatest impact, the focus of school evaluation should either be linked to or have an effect on the focus of teacher evaluation [37]. Taking forward human resources management should ideally be embedded in a system of school quality assurance, where the school strategy and the school- evaluation results ensure a continuous monitoring and improvement of school and teacher quality. Figure 1 below provides a summary of the aspects involved and the way they interconnect. It elaborates on the main components of a comprehensive teacher evaluation model and elucidates the main aspects to be taken into account for designing a conceptual teacher evaluation model. In the framework six main interrelated aspects are presented. They are discussed as follows:

i. Unit Assessed: Individual teacher is the subject of the evaluation which is at the core-centre of the evaluation framework. However it has a link with other components such as student assessment, school evaluation and system evaluation.

ii. Aspects Assessed: Teachers evaluation processes here concentrate on classroom activities and teachers professional development typically covering pedagogical skills, content knowledge, professional competency and professional advancement.

iii. Evaluators: This aspect is mostly concerned with those who have the capability to evaluate and to use the results of an evaluation. It relates to the involvement of a range of stakeholders such as government, students, teachers, school leaders, teacher unions, educational administrators and policy makers in the development and implementation of teachers' evaluation and assessment processes.

.iv. Evaluation Technology: This refers to the features of a given approach to teachers' evaluation (that is the mix of instruments, criteria and standards used in a specific teacher's evaluation model). This may be based on a range of instruments such as classroom observation, data from students, self evaluation, school evaluation, and interviews focused on both improvement and accountability purposes. Hence, this aspect refers to the way different aspects are combined to produce an improve teachers' performance evaluation model in higher institutions.

v. Purposes: This encompasses the objectives of a particular teachers' performance evaluation process and the mechanisms designed to ensure that evaluation results are used in such a way that the objectives are reached or achieved. The purpose of a teacher evaluation process typically consists of improvement and accountability. Examples of the evaluation feedback include performance improvement, career advancement, tenure decisions, rewards and sanctions, all pointing to the central objectives of improving student outcomes and standard of education.

vi. Users of the feedback: This includes the assessed teacher, school authorities, education administrators e.t.c. To teachers, for improvement on areas of weakness, to the school authorities for decision making and to administrators for policy making.

\section{Component Analysis Of The Proposed System}

The proposed system aims to aid the higher institution management in determining teachers' performance from the two instruments proposed in this work (formative and summative), and recommend necessary actions to be taken on individual teacher based on the prediction from the intelligent evaluation system. The proposed system framework aggregates four components: The first component is the data acquisition and storage, responsible for storing teachers' data, gathered from different data sources proposed in a data warehouse. The second component is the model building, responsible for obtaining knowledge about the teachers, through appropriates classification models. Different classification algorithms are proposed in search for the best model with high predictive accuracy. The third component is for mapping the pattern in the rules generated with the teacher data to predict performance and the fourth component is the recommendation, responsible for recommending necessary action to be carried out on individual teacher based on the prediction from the intelligent evaluation system. See Figure 2 . 

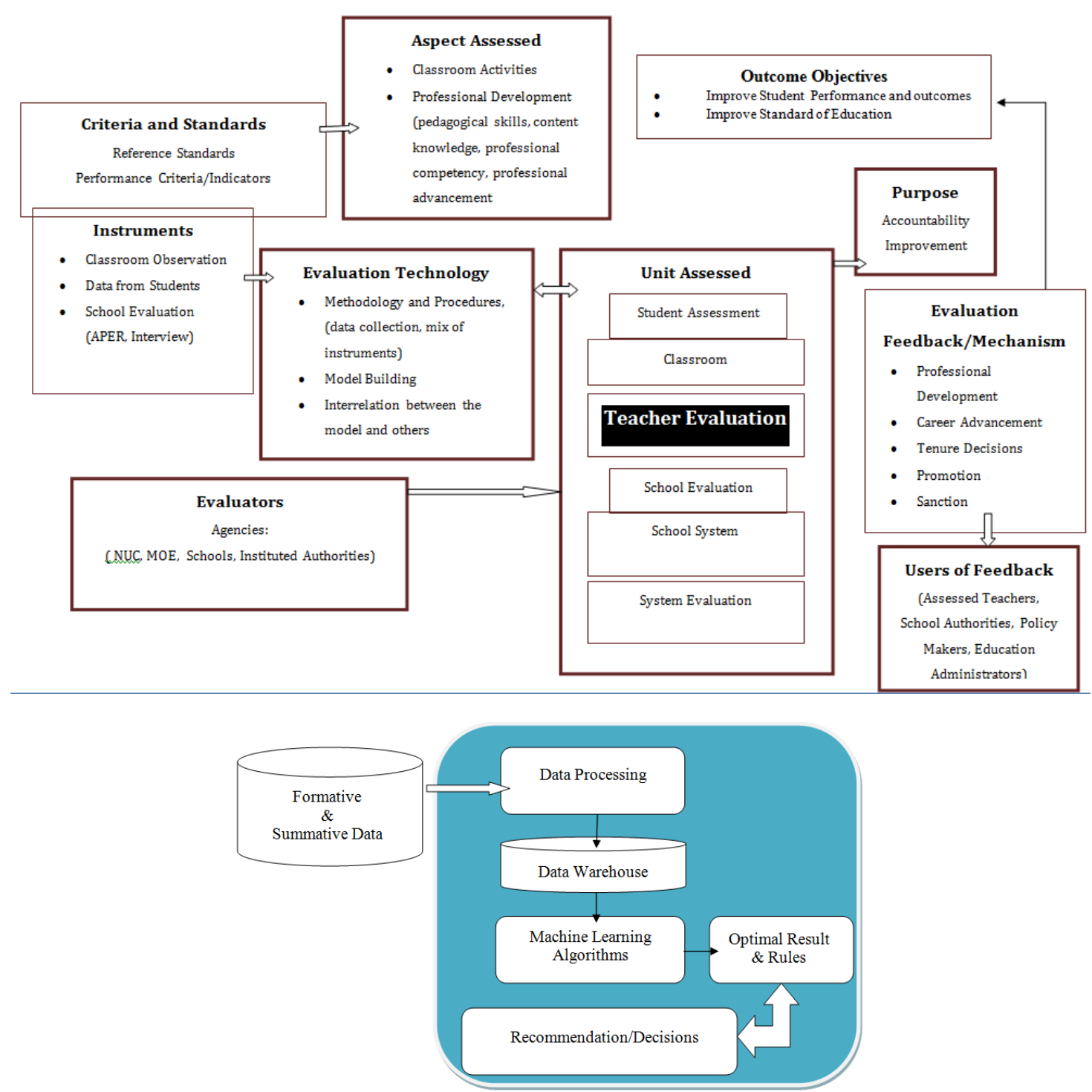

Figure 2: The Framework of the Intelligent Evaluation System- (IES)

\section{Conclusion}

The need for designing an improved and intelligent model for evaluation of instructors' performance in higher institutions especially in the developing countries has become necessary in order to improve efficiency and equity in schooling, effectiveness of learning system and raise educational standards, improving the efficiency of evaluation system and overcome the limitations of the classical methodologies. Consequently, it will help in no small measure in the new move for educational reform efforts. Using factors obtained from randomly selected stakeholders, a framework was proposed for apt teachers' evaluation system. The framework was designed with some of the basic components considered by the authors for reliability. It also provides evaluation and improvement components that can be used to interact with the other components to ensure data and system integrity.

\section{References}

[1] O. Adebanjo, Falling Educational Standards in Nigeria. Caleb University Imota, Lagos. Available online at: http://www.ngex.com/news/public/article.php?ArticleID=2178. Niger Exchange News 1. (2012). Retrieved 30 $0^{\text {th }} \mathrm{July}, 2013$.

[2] A. A. Adediwura, and T. Bada ,Perception of Teachers' Knowledge, Attitude and Teaching skills as Predictor of Academic Performance in Nigerian Higher Schools. Educational Research and Review Vol. 2 (7), pp. 165-171, July 2007. ISSN 1990-3839 (C) 2007 Academic Journals (2007):

[3] O.A. Asikhia, Students and Teachers' Perception of the Causes of Poor Academic Performance in Ogun State Secondary Schools ( Nigeria): Implication for Counseling for National Development. European Journal of Social Sciences. 13(2):229-242. (2010).

[4] L. Bacow, Performance Assessment Models and Tools from Other Sectors: Lessons for Higher Education A Seminar Paper by Harvard Graduate School of Education Cambridge, MA 02138. Retrieved from http://www.gse.harvard.edu/ppe/programs/highereducation/portfolio/performance-assessment.html(2012). 
[5] F. Henard and S. Leprince, The Path to Quality Teaching in Higher Education London School of Economics and Political Science Publication at the OECD from October 2007 to June 2008.

[6] E.S Taylor and J.H. Tyler, The effect of evaluation on teacher performance. Publication of American Economic Review, 102(7), 3628-3651. Available online at http://cepa.stanford.edu/content/effect-evaluation-teacher-performance\#sthash. VFt1w51z.dpuf (2012).

[7] M. William, Research-Based Options for Education Policymaking-“Teacher Evaluation”. National Education Policy Centre (NEPC). Available online at: http://nepc.colorado.edu/publication/options and http://nepc.colorado.edu(2012).

[8] D. Andrew, O. Bankole and A. Olatunde, Labor Market Prospects of University Graduates in Nigeria. Publication of Nigeria University System Innovation Project. November 2010.

[9] S. Chiemeke, O.B. Longe,, F.A. Long end I.O. Shaib, Research Outputs from Nigerian Tertiary Institutions: An Empirical Appraisal . Journal Publication of the Library Philosophy and Practice 2009.ISSN 1522-0222. Available online at: www.webpages.uidaho.edu/ mbolin/chiemeke-longe-shaif.htm., (2009).

[10] S. Glazerman, D. Goldhaber, S. Loeb, S. Raudenbush, D. Staiger. and G.J.R. Whitehurst, Evaluating Teachers: The Important Role of Value-Added. The Brookings Brown Center Task Group on Teacher Quality Pg 2. November 17, 2010.

[11] M. McFarland-McDaniels, How to Design an Evaluation Instrument for a Teacher's Performance. A Publication of $\quad E$ How Education Group. Available online athttp://www.ehow.com/how 8100468 design-evaluation-instrument-teachersperformance.html\#ixzz2XeNE0gs2 (2012).

[12] L.W. Anderson and L.A. Van Dyke, Secondary School Administration: Houghton Mifflin Company, Boston, U.S.A. (2000)

[13] A. Denisi and R. Pritchard, Performance Appraisal, Performance Management, and improving individual performance: A motivational framework. Management and Organization Review, 2(2), 253-277. (2006).

[14] K. Manasa, and N. Reddy, Role of Training in Improving Performance. The IUP Journal of Soft Skills, 3, 72-80. (2009).

[15] F. Hénard and D. Roseveare, Fostering Quality Teaching in Higher Education:Policies and Practices. An IMHE Guide for Higher Education Institutions. .(2012)..

[16] . S.A. Jusoff, .A. Samah, and P. M. Isa, "Promoting university community's creative citizenry," in Proceeding of World Academy of Science, 2008, pp. 1-6.

[17] K. Jenrbaun (2012). Evaluation of College Instructors' Teaching Competencies Towards Proposed Human Resource Development Program. Retrieved from http://www.studymode.com/essays/Evaluation-Of-College-Instructors-Teaching-Competencies$1293750 . \mathrm{html}$

[18] S. Mardikyan, B. Badur, Analyzing Teaching Performance of Instructors Using Data Mining Techniques. Journal of Informatics in Education, 2011, Vol. 10, No. 2, 245-257 245. (2011).

[19] J.Abu-Doleh and D.Weir, Dimensions of Performance Appraisal Systems in Jordanian Private and Public Organizations. International Journal of Human Resource Management, 18(1), 75-84. (2007).

[20] I. A. Archibong, and M.E. Nja, Towards Improved Teaching Effectiveness in Nigerian Public Universities: Instrument Design and Validation. Journal of the Higher Education Studies, Canada. Vol. 1, No. 2; December 2011 URL: http://dx.doi.org/10.5539/hes.v1n2p78.

[21] E.D. Nakpodia, E.D, A Critique of the Methods of Evaluating the Competency of Lecturers in Nigerian Tertiary InstitutionsAfrican Journal of Education and Technology, Volume 1 Number 1, April 2011; pp. 53-59.

[22] R.L. Rothstein, H.F. Ladd, D. Ravitch, E.L. Baker P.E Barton L. Darling-Hammond, E. Haertel, R.L. Linn, R.J . Shavelson, and L.A. Shepard, Problems with the Use of Student Test Scores to Evaluate Teachers. A Publication of Economic Policy Institute. Retrieved from http://www.epi.org/publication/bp278/, (2010).

[23] O.K. Chaudhari P.G. Khot, and K.C. Deshmukh , Soft Computing Model for Academic Performance of Teachers Using Fuzzy Logic. British Journal of Applied Science \& Technology 2(2): 213-226, 2012.

[24] K. Bain. (2004). What the Best College Teachers Do. Cambridge, MA: Harvard Press.

[25] M. Isoré, Teacher Evaluation: Current Practices in OECD Countries and a Literature Review, OECD Education Working Papers, No. 23, OECD Publishing. doi: 10.1787/223283631428. (2009),

[26] J.A. Kulik, Student ratings: validity, utility, and controversy. In: Theall M., Abrami, P.C. Mets, L.A. (Eds.), New Directions for Institutional Research. Jossey-Bass, 109, 9-24. . (2001).

[27] H.W. Marsh and L.A Roche, The use of students' evaluations and an individually structured intervention to enhance university teaching effectiveness. American educational research journal, 30(1), 217-251. (1997).

[28] J. Ory, Teaching Evaluation: past, Present, and Future. New Directions for teaching and learning, No. 83, Fall 2000.

[29] M. Theall. And J. Franklin, Looking for bias in all the wrong places: A search of truth or a witch hunt in student ratings of instruction? New Directions for Instructional research 109: 45-56. (2001)

[30] J. Vollmer, Our Schools Need to Change: http://www.studymode.com/essays/Evaluation-Of-College-Instructors-TeachingCompetencies-1293750.html, http://www.jamievollmer.com/about.html(1987).

[31] UNESCO, Evaluación del Desempeño y Carrera Profesional Docente: Una panorámica de América y Europa, Oficina Regional de Educación para américa Latina y el Caribe, UNESCO Santiago, 2007.

[32] W. McKeachi, Student Ratings; The validity of use. American Psychologist v52, No 11, 1218-1225(1997)..

[33] J. Sojka A.K Gupta and D.R Deeter-Schmetz, Student and Faculty perception of Student Evaluation of Teaching: $A$ Study of Similarities and Differences. College Teaching 50(2): 44-49 (2002).

[34] O.M Okoro, O.M, Program Evaluation in Education. Obosi Nigeria: Pacific Publishers, Uruowulu-Obosi, Anambra State, Nigeria. (1991)

[35] C. Guarini. and B. Stacy, Review of Gathering Feedback for Teachers. Boulder, CO: National Education Policy Center. Retrieved from http://nepc.colorado.edu/files/pb-options-1-teval 1.pdf. (2012).

[36] J.L Steele, L.S. Hamilton, and B.M. Stecher, Incorporating Student Performance Measures into Teacher Evaluation Systems. $\begin{array}{llll}\text { Palo Alto, } \quad \text { CA: RAND. } & \text { ISBN: } & 978-0-8330-5250-6 . & \text { Retrieved from: }\end{array}$ http://www.rand.org/content/dam/rand/pubs/technical reports/2010/RAND TR917(2010).

[37] OECD, Teacher Evaluation: A Conceptual Framework and Examples of Country Practices. A paper was presented at the OECDMexico Workshop Towards a Teacher Evaluation Framework in Mexico: International Practices, Criteria and Mechanisms, held in Mexico City on 1-2 December 2009

[38] B. Avalos and J. Assael, Moving from resistance to agreement: The case of the Chilean teacher performance evaluation", International Journal of Educational Research, Vol. 45, No. 4-5, pp 254-266. , (2006) 